\title{
HAS THE PANDEMIC CHANGED THE CULTURAL PROFILE OF THE YOUNGEST SPORTS TEACHERS?
}

\section{Constanța-Valentina MIHĂIL $\breve{A}^{1 *}$, Gabriela Alina PARASCHIVA ${ }^{2}$, Laurențiu Mihai MIHĂIL $\breve{A}^{3}$}

\footnotetext{
${ }^{1}$ National University of Physical Education and Sport, Faculty of Physical Education and Sport, Bucharest, Romania

${ }^{2}$ Politehnica University, Faculty of Management in Production and Transportation, Timişoara, Romania

${ }^{3}$ Valahia University, Târgoviște, Romania

*Corresponding author: constanta.mihaila@unefs.ro
}

https://doi.org/10.35189/dpeskj.2021.60.4.13

\begin{abstract}
Restrictive measures, protection measures such as wearing masks, remote work, all meant to limit the explosive growth in the incidence of coronavirus disease (COVID-19), have changed people's habits, lifestyles and professional activities. These unexpected and turbulent times have also affected several sectors, such as culture and education, which had to adapt and adjust in order to continue to provide services, but within some limits. Having as background the results of a previous case study developed between 2017 and 2019, this paper aims to analyse whether the cultural features of the newest teachers in the field of sport and physical education science have changed under the impact of the pandemic. Using four of the cultural dimensions of Hofstede's model, an instrument validated at national level in Romania, as well as data collected in the 2020-2021 school year from a group of 32 people (included in a master's programme in the field of sport and physical education science), this paper compares the cultural profile of sport specialists before and during the pandemic. The results show that there are some differences only for two cultural dimensions, namely Masculinity versus Femininity and Power Distance. However, as the spread of coronavirus disease at community level has not yet been stopped, it is very likely that these differences will deepen, greatly affecting pedagogical and managerial practices in schools.
\end{abstract}

Keywords: cultural profile, sport specialist, impact of the pandemic.

\section{Introduction}

The year 2020 could be a landmark in the history of mankind. At this point, it appears as a moment of rupture between before and after the rapid and dramatic spread of coronavirus disease (COVID-19). If until recently people were talking about the changes due to new technologies, globalisation or global warming, a new perspective has emerged, namely that of changes induced by the pandemic. These changes could be felt immediately or are to be seen within a certain period of time.

Firstly, there have been visible changes in our daily lives: distancing protocols; social isolation and mobility restrictions; cancellation and/or postponement of large-scale sporting events; sporting events developed without in-situ live supporters; closure of places for entertainment (theatres, cinemas) and sport (gyms, swimming pools); extensive hygiene protocols and greater sanitary rigor.

Secondly, there have been changes in our lifestyles, habits and ways of thinking and reacting. In this regard, some recent research highlights that the effects can be seen in: 
- diet changes - during quarantine, the diet quality improved due to the increase in homemade meals; diet changes were found to be associated with factors such as time, skills, habits, feelings and beliefs (Artigiani Lima Tribst et al., 2021);

- behavioural changes - due to the rapid spread of COVID-19 infection, some behavioural norms changed in urban areas from a lifestyle based on regular economic cycles within weekdays and holidays to a lifestyle based on infection status and climatic condition (Morita et al., 2020); because of social isolation, personal and collective vulnerabilities were exacerbated, leading to an increase in domestic violence (Bradbury-Jones \& Isham, 2020; Usher et al., 2020);

- changes in work-related attitudes (job motivation and job satisfaction) - increased job insecurity and organizational changes caused by the pandemic were found to be strong predictors of turnover intentions for employees in hospitality industry (even if they were among the survivors, they were afraid of losing their jobs); moreover, job insecurity, risk-taking behaviour and organizational changes were found to be significantly correlated (in a negative way) with job satisfaction (Bajrami et al., 2021);

- changes in human resource management - in order for companies to adapt and survive during the pandemic, human resource management introduced online processes; in addition, employees benefited from new training programmes aimed at developing both the skills required to perform current jobs and those necessary for the future, in the event that the circumstances change (Gigauri, 2020);

- changes in purchasing frequency - between the pre-COVID period and June 2020, the frequency of purchasing certain food products decreased due to the changed shopping habits of the population (from face-to-face shopping to e-commerce using online door-to-door delivery platforms); moreover, commitments to local food procurement (from local farmers/merchants) increased during the COVID period (Carolan, 2021).

Thirdly, the economic impact was massive, as highlighted in detail by two reports of the International Labour Organization (ILO) and World Bank (WB):

- In January 2021, the seventh edition of the ILO Monitor showed the level of decline in the labour market in 2020 due to the pandemic: " 8.8 per cent of global working hours were lost relative to the fourth quarter of 2019, equivalent to 255 million fulltime jobs" (International Labour Organization, 2021, p. 1).

- In January 2021, the World Bank (2021) issued an economic analysis of the year 2020, stating that the global recession caused by COVID-19 was surpassed only by three major events in the last 150 years: World War I, the Great Depression and World War II. According to the WB report, the living standards fell sharply and severely (due to the fact that global economy was estimated to have contracted by $4.3 \%$ and per capita income fell by more than $90 \%$ in developing economies); moreover, the accumulation of human capital was lost since more than $90 \%$ of students had their classes disturbed in one form or another.

In this respect, previous research in the economics of education highlights that schooling years have an impact on the country's income level (Barro \& Lee, 2015; Psacharopoulos \& Patrinos, 2018) and that each additional schooling year will increase life income by about 
$8.8 \%$ (in high-income countries, by $8.2 \%$; in middle-income countries, by $9.2 \%$; in lowincome countries, by $9.3 \%$ ). Therefore, according to the latest estimates, this means that a country's GDP will drop by $1.5 \%$ on average due to losses caused only in the first four months of the pandemic (Hanushek \& Woessmann, 2020).

However, what caught our attention were not the economics of education but the changes in people's lifestyles, habits, attitudes and ways of thinking and acting. Since such issues correlate with different layers of a culture at the level of a country and/or occupation/profession and/or organization, then the logical question that we ask ourselves is: have cultural changes already occurred?

The term 'culture' originated in anthropology in the late 18th century as a "complex whole which includes knowledge, belief, art, morals, law, custom and any other capabilities and habits acquired by man as a member of society" (Tylor, 1871, p. 1) and received other various clarifications and extensions over the years. For this reason, our option was for one of the most popular definitions of the 19th century: "the collective programming of the mind that distinguishes the members of one group or category of people from others" (Hofstede et al., 2010, p. 6) and one of the most popular cultural frameworks proposed so far for national culture, namely that developed by Hofstede and then extended by Hofstede et al. (2010). The initial framework included four dimensions:

- Power Distance (targeting the acceptance of the unequal distribution of power in a society),

- Uncertainty Avoidance (targeting people's tolerance to unknown/unpredictable situations),

- Masculinity versus Femininity (targeting the emotional gender roles of men and women in a society and their distribution),

- Individualism versus Collectivism (targeting the integration of individuals into groups),

to which two more dimensions were later added:

- Long-Term versus Short-Term Orientation (targeting people's choice to focus on the past, present or future),

- Indulgence versus Restraint (targeting the human desire to enjoy life and the way society treats it).

Previous research and analysis have shown that the cultural profile initiated at national level can be continued with a cultural profile of organizational and occupational levels (Mihail, 2001; Hofstede et al., 2010; Iosifescu et al., 2013; Helmreich \& Merritt, 2017).

Therefore, this paper is aims to analyse possible changes in the cultural profile of sport specialists. It will compare the cultural profile of the newest teachers in the field of sport and physical education science before and during the pandemic, having as background the results of a previous case study developed between 2017 and 2019. The results can be used to personalise pedagogical and managerial practices in schools. 


\section{Methodology}

In methodological terms, we used an instrument validated at national level in Romania within the project "Quality Education in Rural Schools" (implemented by ARACIP between 2013-2015 and funded by ESF); it is a 35-item questionnaire that covers the four initial cultural dimensions of Hofstede's model: Power Distance, Uncertainty Avoidance, Masculinity versus Femininity and Individualism versus Collectivism, for which the subsequent items of each field (dimension) are correlated, showing internal consistency and therefore being able to provide a picture of each dimension under study.

Although the other two dimensions (Long-Term versus Short-Term Orientation and Indulgence versus Restraint) had been added to the Hofstede's original cultural model at the time when we started our investigation, for comparability reasons, we decided to limit our study to the first four initial dimensions. In this way, the results could be compared with those of a previous case study conducted between 2017 and 2019 on 3 groups (65 people included in a master's programme in the field of sport and physical education science).

In terms of pursued dimensions, the 35 items of the questionnaire were distributed as follows: 10 survey items to cover Power Distance, 11 survey items to cover Uncertainty Avoidance, 8 survey items to cover Masculinity versus Femininity and 6 survey items to cover Individualism versus Collectivism. Each of them had to be scored by respondents on a Likert scale that captured the intensity of their feelings for a given statement: 1 point for "Strongly disagree", 2 points for "Disagree", 3 points for "Neither agree nor disagree", 4 points for "Agree" and 5 points for "Strongly agree".

The research sample consists of a group of 32 people included in a master's programme in the field of sport and physical education science in the 2020-2021 school year. The questionnaire was sent to 32 students and we collected feedback from all 32 participants ( $100 \%$ feedback); in terms of gender distribution, $25 \%$ of them were female ( 8 respondents) and $75 \%$ were male ( 24 respondents); in terms of age distribution, $87.5 \%$ of them were between 21 and 26 years (28 respondents) and $12.5 \%$ were between 26 and 43 years (4 respondents). This means that the group of young people was predominantly male.

The responses were sorted and clustered according to the cultural dimension pursued, resulting in 4 clusters with series of data for which the mean scores varied together. For each cluster, both Shapiro-Wilk tests (for data normality) and the calculation of Pearson's coefficient of variation (for data homogeneity) were scheduled and performed. In these conditions, a factor score per cluster (named index) could be defined as the arithmetic mean of the scores rated for each item:

- a Power Distance index (PDI), ranging from 10 points (for small power distance) to 50 points (for large power distance);

- an Uncertainty Avoidance index (UAI), measuring the level of tolerance to uncertain/ unpredictable situations and ranging from 11 points (for weak uncertainty avoidance) to 55 points (for strong uncertainty avoidance);

- a Masculinity versus Femininity index (MAS), measuring the degree of masculinity and ranging from 8 points (for the most feminine) to 40 points (for the most masculine); 
- an Individualism versus Collectivism index (IDV), measuring the degree of individualism and ranging from 6 points (for high individualism) to 30 points (for high collectivism).

Finally, we compared currently extracted values with previous ones for each index (valid for the period 2017-2019) and we drew some conclusions in terms of both developments and intrinsic value of each index.

\section{Results}

The prerequisite assessment of data normality was statistically approached using ShapiroWilk tests to compare the scores in each cluster with a normally distributed set of scores having the same mean and standard deviation; the null hypothesis (H0) was set as "the sample distribution is normal", the alternative hypothesis (H1) was set as "the sample distribution is not normal", and the significance threshold was $p=.05$. Four normality distribution Shapiro-Wilk tests were performed, and the results are shown in Table 1, where "Statistic" is the $W$ value for the Shapiro-Wilk test, "df" is number of analysed values, and "Sig." is the probability of occurrence of the $W$ value (rounded to three decimal places).

Table 1. Results of normality tests inside cultural dimension clusters

\begin{tabular}{lcccc}
\hline \multirow{2}{*}{ Cultural dimension clusters } & \multicolumn{3}{c}{ Shapiro-Wilk } & Result \\
\cline { 2 - 5 } & Statistic & Df & Sig. & Null hypothesis \\
\hline Power Distance & .983 & 23 & .872 & accepted \\
Uncertainty Avoidance & .939 & 23 & .070 & accepted \\
Masculinity versus Femininity & .943 & 23 & .090 & accepted \\
Individualism versus Collectivism & .933 & 23 & .048 & rejected \\
\hline Source: authors' own development using SPSS processing
\end{tabular}

Only in the case of the Individualism versus Collectivism cluster, the test was found to be statistically significant (due to the fact that the significance value was below .05); this means that the requirement for normal data distribution is met in 3 out of 4 cultural dimension clusters. Therefore, we decided to exclude the Individualism versus Collectivism cluster from the homogeneity tests.

The prerequisite assessment of data homogeneity was statistically approached using Pearson's coefficient of variation - $C v=\mathrm{Std}$. Deviation/Mean $* 100$. For each of the three remaining data series, the $C v$ value was calculated, and the results are shown in Table 2.

Table 2. Results of homogeneity tests inside cultural dimension clusters

\begin{tabular}{|c|c|c|c|c|c|}
\hline Cultural dimensions & Sum & Mean & $\begin{array}{c}\text { Std. } \\
\text { Deviation }\end{array}$ & $C v$ & $\begin{array}{c}\text { Degree of } \\
\text { homogeneity }\end{array}$ \\
\hline Power Distance & 1018 & 31.8125 & 3.39295 & 10.66546 & $\begin{array}{c}\text { relatively } \\
\text { homogeneous }\end{array}$ \\
\hline Uncertainty Avoidance & 1211 & 37.8438 & 4.03300 & 10.65696 & $\begin{array}{c}\text { relatively } \\
\text { homogeneous }\end{array}$ \\
\hline Masculinity versus Femininity & 748 & 23.3750 & 4.17172 & 17.84693 & $\begin{array}{c}\text { relatively } \\
\text { homogeneous }\end{array}$ \\
\hline
\end{tabular}


As $10 \%<C v<20 \%$ for each case, it results that each of the analysed data series is relatively homogeneous; in addition, this means that the central tendency indicators are sufficiently representative for each of the series; in other words, the mean value for each cluster is representative for the entire series.

Since three series of data met both the conditions of normality and homogeneity, we then proceeded to extract the index value for each and compare them with the values extracted in our previous case study, which was conducted between 2017 and 2019 on a sample of 65 people included in a master's programme in the field of sport and physical education science. The results of the previous situation (case study) and those of the current situation (case study) obtained before and after the rapid and dramatic spread of coronavirus disease (COVID-19) are shown in Table 3.

Table 3. Differences for PDI, UAI and MAS (previous and current values)

\begin{tabular}{lccc}
\hline \multicolumn{1}{c}{ Index } & Previous value & Current value & Differences \\
\hline PDI & 32.8 & 31.8125 & existing, but possibly insignificant \\
UAI & 37.8615 & 37.8438 & insignificant \\
MAS & 21.8615 & 23.3750 & existing, but possibly insignificant \\
\hline \multicolumn{2}{l}{ Source: authors' own development using data from a previous sample (65 people) and the current sample (32 people) }
\end{tabular}

The results indicate that there are some differences only for two cultural dimensions, namely Power Distance and Masculinity versus Femininity: but are they significant or not? In order to analyse this issue, additional assessments are required.

Thus, we decided to perform the $z$-parameter test (two-tailed) to compare the mean values of each sample - one test to compare the mean of the previous sample for Power Distance with the mean of the current sample for the same cultural dimension and a similar test for the cultural dimension of Masculinity versus Femininity. Therefore, two parametric bilateral tests were performed having as background: the null hypothesis (H0) - "the compared values do not differ from each other" (in other words, the mean difference between the values of the previous and current samples is not significantly different from zero); the alternative hypothesis (H1) - "the compared values differ from each other" (in other words, the mean difference between the values of the previous and current samples is significantly different from zero). The significance threshold $\alpha=.05$ and the critical region for the test $(-\infty ;-1.96]$ $\cup[1.96 ; \infty)$ were used, and the results are shown in Table 4 .

Table 4. Results of additional assessments for significant differences

\begin{tabular}{lcccccc}
\hline \multirow{2}{*}{ Cultural dimensions } & \multicolumn{2}{c}{ Previous sample } & \multicolumn{2}{c}{ Current sample } & \multicolumn{2}{c}{$z$ Test } \\
\cline { 2 - 7 } & Mean & Variance & Mean & Variance & $z$ value & Sig. \\
\hline Power Distance & 32.8 & 15.267 & 31.812 & 11.152 & -1.292 & .196 \\
Masculinity versus Femininity & 21.861 & 14.303 & 23.375 & 16.859 & 1.751 & .079 \\
\hline Source: authors' own development using the significance threshold $\alpha=.05$ & and the critical region for the test $(-\infty ;-1.96] \cup[1.96 ; \infty)$
\end{tabular}

The results indicate that the $z$ value is outside the critical region in both cases, which means that both tests are statistically insignificant, and the null hypothesis cannot be rejected. 
So, although apparently there would be some differences between these two cultural dimensions, actually the compared data series do not differ from each other.

\section{Conclusion}

This research examines the cultural features of the newest teachers in the field of sport and physical education science under the impact of the pandemic. The assessments made lead us to the following conclusions:

Firstly, with regard to PDI, although apparently there would be some differences between the two samples (given that before PDI $=32.8$ and during the pandemic PDI $=31.812$ ), actually the compared series of data do not differ from each other. The PDI value ranges from 10 points (for small power distance) to 50 points (for large power distance), which means that the identified index value exceeds the middle position, with an emphasis on power. Therefore, in this case: teachers rely more on superiors (school managers, subject inspectors) and formal rules than on their own experiences; teachers expect to be told what to do rather than be consulted and be part of the decision-making process; the teacher-school manager relationship is more emotional (based on feelings) than pragmatic (based on results).

Secondly, with regard to UAI, no differences were found between the two samples (given that before $\mathrm{UAI}=37.86$ and during the pandemic $\mathrm{UAI}=37.84)$. The UAI value ranges from 11 points (for weak uncertainty avoidance) to 55 points (for strong uncertainty avoidance), which means that the identified index value exceeds the middle position, showing a tendency to avoid uncertainty. Therefore, in this case: teachers are motivated by security and peace at work rather than achievements during classes; teachers need formalisation and precision to complete a task, as opposed to having the freedom to choose their own way of solving a task; teachers perform better on implementation doing well what they already know than on innovation, which involves creating new pedagogical approaches and/or new auxiliary teaching aids; teachers hardly leave the assumptions deeply rooted in the collective mind or acquired during the initial training in favour of new approaches (whose appearance is normal and in line with the development of pedagogical concepts and/or the development of the subject they teach).

Thirdly, with regard to MAS, although apparently there would be some differences between the two samples (given that before MAS $=21.86$ and during the pandemic MAS $=$ 23.37), actually the compared series of data do not differ from each other. The MAS value ranges from 8 points (for the most feminine) to 40 points (for the most masculine), which means that the identified index value is close to the middle position, showing a slight tendency towards femininity. Therefore, in this case: teachers do not consider that the strongest should win in conflict resolution, leaving too little room for compromise and negotiation; teachers do not seek to secure their own careers (professional positions), have access to essential information and earn more money/resources (which ensures them a privileged position relative to peers), but try to collaborate and work in a team, sharing information and resources.

And fourthly, with regard to IDV, the Shapiro-Wilk test indicates that there is no normal data distribution for the current sample; the mean value for the Individualism versus Collectivism cluster, calculated at 21.83 , is not representative for the entire series, the values 
obtained being at extremes. Therefore, in this case: some teachers give priority to personal initiatives and achievements, while others give priority to the group and its achievements; for some teachers, intrinsic factors (such as satisfaction with job and personal development, feelings of accomplishment and fulfilment when completing a task) are the real motivators, while for others, extrinsic factors (such as income level, various bonuses, promotions) are the real motivators.

Therefore, according to the measurements made, no cultural changes have occurred at professional level under the impact of the pandemic.

However, the limitation of this paper is given by the fact that the present data were collected in November 2020, at a time when the first pandemic shock had passed and the general perception of the population was that the problems had been overcome, but the second pandemic wave had just begun. As the spread of coronavirus disease at community level has not yet been stopped, it is very likely that the differences in the cultural dimensions of Power Distance and Masculinity versus Femininity will deepen and became significant.

However, although cultural changes at the level of organization or profession are much more dynamic than those at national level, the time interval between the two measurements was short, and the changes may not be visible yet. Therefore, we believe that a new data collection is needed at the end of 2021 in order to have a clearer perspective.

Anyway, the projected cultural profile is surprising, taking into account that the previous and current samples are predominantly made up of young people at the beginning of their teaching careers; it shows that teachers are not autonomous enough and not creative enough. This profile should also be considered by school managers and school inspectors for personalised pedagogical and managerial approaches.

\section{References}

Artigiani Lima Tribst, A., Raulino Tramontt, C., \& Galastri Baraldi, L. (2021). Factors associated with diet changes during the COVID-19 pandemic period in Brazilian adults: Time, skills, habits, feelings and beliefs. Appetite, 163: 105220. https://doi.org/10.1016/j.appet.2021.105220

Bajrami, D. D., Terzić, A., Petrović, M. D., Radovanović, M., Tretiakova, T. N., \& Hadoud, A. (2021). Will we have the same employees in hospitality after all? The impact of COVID-19 on employees' work attitudes and turnover intentions. International Journal of Hospitality Management, 94: 102754. https://doi.org/10.1016/j.ijhm.2020.102754

Barro, R. J., \& Lee, J.-W. (2015). Education matters. Global schooling gains from the 19th to the 21 st century. Oxford University Press. https://doi.org/10.1093/acprof:oso/9780199379231.001.0001

Bradbury-Jones, C., \& Isham, L. (2020). The pandemic paradox: The consequences of COVID-19 on domestic violence. Journal of Clinical Nursing, 29(13-14), 2047-1049. https://doi.org/10.1111/jocn.15296

Carolan, M. (2021). Practicing social change during COVID-19: Ethical food consumption and activism pre- and post-outbreak. Appetite, 163: 105206. https://doi.org/10.1016/j.appet.2021.105206 
Gigauri, I. (2020). Influence of Covid-19 crisis on human resource management and companies' response: The expert study. International Journal of Management Science and Business Administration, 6(6), 15-24. http://dx.doi.org/10.18775/ijmsba.1849-5664-5419.2014.66.1002

Hanushek, E. A., \& Woessmann, L. (2020). The economic impacts of learning losses. OECD Education Working Paper No. 225. https://www.oecd.org/education/The-economicimpacts-of-coronavirus-covid-19-learning-losses.pdf

Helmreich, R. L., \& Merritt, A. C. (2017). Culture at work in Aviation and Medicine: National, cultural and professional influences. Routledge. https://doi.org/10.4324/9781315258690

Hofstede, G., Hofstede, G. J., \& Minkov, M. (2010). Cultures and organizations: Software of the mind. Intercultural cooperation and its importance for survival. McGraw-Hill.

International Labour Organization. (2021). ILO Monitor: COVID-19 and the world of work (7th ed.). Geneva.

Iosifescu, C.-S., Mihăilă, C.-V., Munteanu, M.-V., Novak, C., Petrescu, P. C., \& Pop, V. L. (2013). Studiu național privind stadiul dezvoltării culturii calității la nivelul sistemului de invățământ preuniversitar: Sinteză [National study on the stage of development of quality culture in the pre-university education system: Synthesis]. Qual Media.

Mihail, T. M. (2001). Impactul măsurilor de reformă la nivelul unității școlare [The impact of reform measures on the school unit]. ISE București.

Morita, H., Nakamura, S., \& Hayashi, Y. (2020). Changes of urban activities and behaviors due to COVID-19 in Japan. SSRN Electronic Journal. http://dx.doi.org/10.2139/ssrn.3594054

Psacharopoulos, G., \& Patrinos, H. A. (2018). Returns to investment in education. A decennial review of the global literature. Education Economics, 26(5), 445-458. https://doi.org/10.1080/09645292.2018.1484426

Tylor, E. B. (1871). Primitive culture: Researches into the development of mythology, philosophy, religion, art, and custom (Vol. 1). London.

Usher, K., Bhullar, N., Durkin, J., Gyamfi, N., \& Jackson, D. (2020). Family violence and COVID-19: Increased vulnerability and reduced options for support. International Journal of Mental Health Nursing, 29, 549-552. https://doi.org/10.1111/inm.12735

World Bank. (2021). Global economic prospects, January 2021. https://doi.org/10.1596/978-1-4648-1612-3 